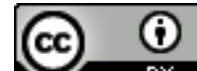

Esta obra está sob o direito de Licença Creative Commons Atribuição 4.0 Internacional.

\title{
MULHERES TRANS E ALOCAÇÃO EM ESTABELECIMENTOS PRISIONAIS: IMPLICAÇÕES PARA O CUMPRIMENTO DA PENA DE PESSOAS TRANSGÊNERAS SOB A ÓPTICA DO STJ NOS PRESÍDIOS ALAGOANOS
}

\author{
Carla Waleska Gomes de Araujo ${ }^{1}$ \\ Nivania Maria Santiago de Arruda ${ }^{2}$
}

\section{RESUMO}

O presente artigo tem objetivo estudar a alocação de mulheres Trans no sistema prisional brasileiro, sob à luz do STJ. Tomando como ponto de partida a diferença entre gênero e sexo, abre-se um questionamento a respeito da alocação de um indivíduo transexual a uma unidade prisional: Uma mulher trans deve ser alocada em um presídio masculino ou feminino? A metodologia utilizada foi a de compilação bibliográfica e estudo dos posicionamentos doutrinários, artigos e notícias. Inicialmente aborda- se, em uma visão geral, o conceito de transexualidade e a identidade de gênero. Em seguida, há o detalhamento dos direitos e garantias dos LGBT's, sob o olhar dos instrumentos protetivos internacionais e nacionais, bem como a análise Habeas Corpus $n^{\circ} 152.491$ pelo STF. Ao final, será analisado como ocorre o cumprimento de penas de mulheres trans nos presídios alagoanos.

Palavras-chave: Mulher Trans. Sistema Penitenciário. Direito

\footnotetext{
${ }^{1}$ carlawaleska@hotmail.com
}

2 nivaniamaria@hotmail.com 


\section{INTRODUÇÃO}

Nos últimos anos, a questão da diversidade sexual e identidade de gênero. tem sido motivo de estudos em todo o mundo.

Dentro desta temática, há a necessidade de voltar-se para o sistema penitenciário, visto que neste local elas vivenciam punições não só pelo crime cometido, mas também pela expressão de suas identidades, principalmente pelo regime binário de gênero das prisões brasileiras. São inúmeros os relatos de estupros coletivos, cabelos cortados à força, hormonizações interrompidas bruscamente, imposição do uso de vestimentas e da permanência em celas masculinas, o que não condiz com suas identidades de gênero.

Assim sendo, o objetivo do presente trabalho é investigar qual o lugar do cumprimento da pena de privação de

\section{METODOLOGIA}

Trata-se de uma revisão de literatura tradicional, não sistemática, descritiva, de

\section{RESULTADOS E DISCUSSÕES}

\section{Breve conceito de pessoas transgêneras}

Inicialmente, para um maior entendimento do assunto, faz-se necessário entender o que é transgeneridade. Faz-se necessário então compreender transexualidade para entender a diferença liberdade da mulher trans no sistema prisional alagoano.

Tomando como ponto de partida a diferença entre gênero e sexo, abre-se um questionamento a respeito da alocação de um indivíduo transexual a uma unidade prisional: Uma mulher trans deve ser alocada em um presídio masculino ou feminino?

A metodologia utilizada foi a de compilação bibliográfica e estudo dos posicionamentos doutrinários, artigos e notícias, partindo do conceito de pessoas transgêneras, analisando a legislação nacional e internacional voltada para a proteção das pessoas transgêneras, com destaque para o Habeas Corpus n ${ }^{\circ} 152.491$, julgado pelo Supremo Tribunal Federal. Ao final, foi detalhado os critérios utilizados pelo sistema penitenciário alagoano para alocar as mulheres trans.

natureza qualitativa, com análise de conteúdo de livros e documentos adquiridos em bibliotecas físicas e virtuais.

entre sexo biológico e gênero.

Martins (2014) ao diferenciar gênero de sexo afirma que sexo refere-se à identidade biológica de uma pessoa; gênero, por sua vez, está ligado à sua construção social como sujeito masculino e feminino, focalizando os processos de formação da feminilidade e masculinidade. 
Assim, o termo sexo se refere ao biológico, voltado para o masculino ou feminino, e o á o termo gênero se refere à produção social como masculino ou feminino.

Pinto (2003) ao analisar as relações entre sexo e gênero afirma que na maioria dos casos, a identidade de gênero corresponde ao sexo biológico, em que pessoas nascidas com o sexo masculino se identificam em sua subjetividade como homens, ou pessoas que nasceram com o sexo biológico femininos e identificam como mulheres. Porém, nem sempre há tal correspondência, o que define-se como transexualidade, em que a identidade de gênero não condiz ao sexo biológico

Neste contexto, uma pessoa transexual pode ser definida como alguém que busca adequar-se a sua identidade de gênero, sendo reconhecida pelo gênero e não pelo sexo biológico.

Bento (2008) define que os transexuais são pessoas que ousam reivindicar uma identidade de gênero em oposição àquela informada pela genitália e ao fazê-lo pode ser capturado pelas normas de gênero mediante a medicalização e patologização da experiência.

Morici (1998) complementa essa definição o transexual reúna em seu corpo todos os atributos físicos de um dos sexos, seu psiquismo pende, irresistivelmente ao sexo oposto. Mesmo sendo biologicamente normal, demonstra um profundo inconformismo com o sexo anatômico e intenso desejo de modificá-lo.

\section{Implicações para o cumprimento da pena de pessoas transgêneras sob a óptica do stf}

Em fevereiro de 2018, o Supremo Tribunal Federal Brasileiro julgou o Habeas Corpus $\mathrm{n}^{\mathrm{o}} 152.491$ que determinou a transferência de duas travestis para uma unidade prisional compatível com suas identidades de gênero, recolocando na esfera pública aspectos relevantes acerca da discriminação que a população LGBTT sofre dentro do sistema prisional.

Devido a sua relevância e considerando a existência de relativamente poucas decisões do STF que envolvem diretamente a sua proteção e promoção do direito da população LGBTT, a decisão se tornou um importante marco para o tratamento jurídico do tema.

A mencionada decisão foi fundamentada pelo Ministro Luís Roberto Barroso Resolução Conjunta $\mathrm{n}^{\circ}$, de 15.04.2014, do Conselho Nacional de Combate à Discriminação; e da Resolução SAP n ${ }^{\circ} 11$, de 30.01.2014, do Estado de São Paulo

A Resolução Conjunta $n^{\circ} 1$ do Conselho Nacional de Combate a Discriminação cita os seguintes tratados de direitos humanos que o Brasil retificou:

A Declaração Universal dos Direitos 
Humanos (1948), que regulamentou o direto à Vida; Liberdade; Segurança pessoal; Não tortura; Direito de ser reconhecido como pessoa e Igualdade.

Santos (2020) ao fazer uma releitura desta Declaração Universal, afirma que:

Fazendo uma releitura da Declaração Universal dos Direitos Humanos é possível afirmar que todas as pessoas transexuais $\mathrm{e}$ travestis têm direito à vida, à liberdade e à segurança pessoal (Artigo III), não devem ser submetidas à tortura nem a tratamento ou castigo cruel, desumano ou degradante (Artigo IV). Ademais, é importante afirmar que todas as pessoas transexuais e travestis têm o direito de ser, em todos os lugares, reconhecidas como pessoa perante a lei (Artigo VI), tendo direito, sem qualquer distinção, a igual proteção da lei, inclusive proteção contra qualquer discriminação que viole a presente Declaração e contra qualquer incitamento a tal discriminação (Artigo VII). (Grifo nosso).

Desse modo, a Declaração Universal de Direitos Humanos afirma a igualdade entre os seres humanos, de direitos e deveres, destacando dentro desta o respeito à igualdade o direito à diferença e à diversidade, assegurando-lhes um tratamento especial.

\section{A Convenção Americana de}

Direitos Humanos (Pacto de San José da Costa Rica) (1969) visa garantir o direito à vida, bem como a integridade física, psicológica e moral da pessoa humana.
A Convenção contra a Tortura e Outras Penas ou Tratamentos Cruéis, Desumanos ou Degradantes e seu Protocolo Facultativo (2002), que garante o direito a não tortura e não tratamento cruel. Assim, é dever dos estabelecimentos penais proteger as pessoas que estão privadas, assegurandolhes um tratamento respeitoso e digno.

As Regras Mínimas das Nações Unidas para o tratamento de presos (2015), por sua vez relacionam-se com Respeito à dignidade, não discriminação, segurança, respeito e a autoatribuição de gênero.

Regra 7
Nenhuma pessoa deve ser
admitida num estabelecimento
prisional sem uma ordem de
detenção válida. As seguintes
informações devem ser
adicionadas ao sistema de registro
do recluso, logo após a sua
admissão: Informações precisas
que permitam determinar a sua
identidade, respeitando a
autoatribuiçãa de gênero.
Regra 11

As diferentes categorias de reclusos devem ser mantidas em estabelecimentos prisionais separados ou em diferentes zonas de um mesmo estabelecimento prisional, tendo em consideração o respectivo sexo e idade.

Assim sendo, fica reafirmado o respeito à pessoa presa, independente de sua orientação sexual e/ou de gênero, tanto por parte dos policiais penais quanto pelos funcionários encarregados de fazer cumprir a Lei. 
As Regras das Nações Unidas para o tratamento de mulheres presas (As Regras de Bangkok) (2016) focalizam regras para o tratamento de mulheres presas e medidas não privativas de liberdade para mulheres infratoras.

Os Princípios de Yogyakarta (2007) dispõem sobre a Aplicação da Legislação Internacional de Direitos Humanos em relação à Orientação Sexual e Identidade de Gênero.

Cavalcante (2011) complementa a importância deste olhar diferenciado para o público LGBT afirmando que eles esboçam uma série de normas a nível global, as quais buscam assegurar os direitos humanos eventualmente violados pela orientação de sexual ou identidade de gênero. Tais princípios foram positivados oficialmente em novembro de 2006, na Indonésia. E ao lado de cada um, há recomendações dirigidas aos Estados, resguardando a dignidade da pessoa presa.

Outra resolução citada na decisão é a Resolução SAP no 11, de 30.01.2014, do Estado de São Paulo, que dispõe sobre a atenção às travestis e transexuais no âmbito do sistema penitenciário.

Dentre os parâmetros estabelecidos pela referida Resolução, estão elencados diversos direitos, destacando-se:

Art. $2^{\circ}$ - A pessoa travesti ou transexual em privação de liberdade tem o direito de ser chamada pelo seu nome social, de acordo com o seu gênero. Parágrafo único - O registro de admissão no estabelecimento prisional deverá conter o nome social da pessoa presa.

51 Art. $3^{\circ}$ - Às travestis e aos gays privados de liberdade em unidades prisionais masculinas, considerando a sua segurança e especial vulnerabilidade, deverão ser oferecidos espaços de vivência específicos.

52 Art. $4^{\circ}$ - As pessoas transexuais masculinas e femininas devem ser encaminhadas para as unidades prisionais femininas.

Parágrafo único - Às mulheres transexuais deverá ser garantido tratamento isonômico ao das demais mulheres em privação de liberdade.

53 Art. $5^{\circ}$ - À pessoa travesti ou transexual em privação de liberdade serão facultados o uso de roupas femininas ou masculinas, conforme o gênero, $\mathbf{e}$ a manutenção de cabelos compridos, se o tiver, garantindo seus caracteres secundários de acordo com sua identidade de gênero.

Através desta resolução, há a efetividade dos direitos da população trans encarcerada salvaguarda os direitos e garantias dessas pessoas, embasados no Princípio da Dignidade da Pessoa Humana.

Meirelles (2015) corrobora com este pensamento, reafirmando a importância de um olhar diferenciado para o público trans encarcerados, uma vez que devemos levar em consideração o desdobramento preconceituoso que incide não só na sua condição transexual, com também na sua condição enquanto privado de liberdade. 
Ainda convém lembrar $\mathrm{O}$ ministro Barroso (2019) justificou a sua decisão fazendo referência à Constituição Federal de 1988 que estabeleceu um Estado Democrático de Direito com o objetivo de assegurar o exercício dos direitos sociais e individuais. Foram citadas proteção: (i) ao direito à vida, à liberdade e à segurança (ii) à vedação à tortura e ao tratamento desumano e cruel e (iii) à proibição de tratamento discriminatório.

Ainda no âmbito Constitucional foram citados vários Princípios como o da dignidade humana, o direito à não discriminação em razão da identidade de gênero ou em razão da orientação sexual, o direito à vida e à integridade física, direito à saúde, vedação à tortura e ao tratamento desumano ou cruel

Portanto, é dever dos Estados de zelar pela não discriminação em razão da identidade de gênero e orientação sexual, devendo adotar todas as medidas necessárias para assegurar a integridade física e psíquica das mulheres transexuais, levando em conta os abusos que sofrem no cárcere. Inclusive alerta que não se trata de uma opção aberta ao poder público, para que se escolha como proceder sobre essa situação, trata-se, porém, de uma imposição decorrente dos princípios constitucionais da "dignidade humana, da liberdade, da autonomia, da igualdade, do direito à saúde e da vedação ao tratamento cruel e à tortura" (STF, 2019, p. 13).

\section{O cumprimento das penas por pessoas transgêneras nos presídios de alagoas}

O Brasil, em 2017, possuía a $3^{\text {a }}$ maior população carcerária do mundo, de acordo com levantamento realizado pelo Conselho Nacional de Justiça (CNJ). Em Alagoas, o número de reeducandos recolhidos em unidades prisionais ultrapassa a marca de 4 mil pessoas. Dentro desse público encontra-se a população composta por lésbicas, gays, bissexuais, travestis e transgêneros (LGBT)

Objetivando assegurar os direitos humanos do segmento LGBT no sistema prisional alagoano, as Secretarias da Ressocialização e Inclusão Social (SERIS) e da Mulher e dos Direitos Humanos do Estado de Alagoas (SEMUDH), elaboraram uma portaria conjunta, tomando como pressuposto a Declaração Universal dos Direitos Humanos e o Plano Estadual de Direitos LGBT.

Neste sentindo, Alagoas é um dos poucos estados do país que tem uma política de atenção voltada para o segmento LGBT, estabelecendo parâmetros para o acolhimento desse público.

A portaria veda qualquer tipo de discriminação fundada na orientação de gênero e cometida por parte de funcionários da administração penitenciária ou 
particulares. Isso pode ser constatado no art. $2^{\circ}$ in verbis:

Art. $2^{\circ} \mathrm{E}$ vedada toda e qualquer forma de discriminação por parte de funcionários da administração penitenciária ou de particulares fundada na orientação sexual ou na identidade de género da pessoa privada de liberdade, assegurandose aos presos e presas o respeito â sua liberdade de autodeterminação.

Acrescido a isso, a portaria assegura o direito do público LGBT de ser tratado pelo nome social, de acordo com o seu gênero, sendo este mantido no registro no prontuário e todos os demais documentos oficiais gerados pela SERIS

Art. $5^{\circ}$ A pessoa travesti ou mulher e homem transexual em privação de liberdade tem o direito de ser tratada pelo nome social, de acordo com o seu género.

I- Entende-se por nome social aquele pelo qual pessoas travestis, mulheres transexuais e homens transexuais querem ser tratados;

Art. $7^{\circ}$ No momento da realização do procedimento Porta de Entrada deverá ser informado a travesti ou transexual sobre o direito ao tratamento nominal nos atos $\mathrm{e}$ procedimentos da pasta.

$\S 1^{\circ} \mathrm{O}$ nome social informado passara a ser utilizado no Sistema de Administração Penitenciário, em seu prontuário e todos os demais documentos oficiais gerados pela Secretaria de Estado de Ressocialização e Inclusão Social (SERIS);

$\S 2^{\circ} \mathrm{O}$ prenome anotado no registro civil deve ser utilizado para os atos que ensejarão a emissão de documentos oficiais, acompanhado do nome social escolhido.

Além disso, permite-se a implantação de um lugar específico para abrigar travestis e transexuais no cárcere, e estabelece a realização de campanhas educativas sobre a diversidade, orientação sexual e identidade de gênero que devem ser executadas através da Escola Penitenciária.

Art. $8^{\circ}$ As unidades prisionais podem implantar, depois de análise de viabilidade cela ou ala específica para população de travestis e transexuais de modo a garantir sua dignidade, individualidade e adequado alojamento.

$\S 1^{\circ}$ Para isso deve-se analisar o interesse da população assistida evitando assim segregação social ou quaisquer formas de discriminação negativa em razão da identidade de gênero ou orientação sexual.

$\S 2^{\circ}$ Fica assegurado aos travestis e transexuais o uso de roupas intimas, feminina ou masculina, conforme seu gênero, bem como é facultada a manutenção do cabelo na altura dos ombros.

$\S^{\circ}$ A aplicação das medidas acima devem observar os critérios de segurança e disciplina considerando as particularidades de cada estabelecimento prisional.

O que se observa na prática, é que a portaria supramencionada visa assegurar os direitos humanos do segmento LGBT no sistema prisional alagoano. No entanto, em vários aspectos a teoria diverge da prática.

De acordo com o diagnóstico nacional do tratamento penal de pessoas 
LGBT nas prisões do Brasil publicado em 2020. A partir de2017, com a emissão de uma portaria que regulamenta os parâmetros de acolhimento de LGBT nas unidades prisionais do estado de Alagoas, foi criada na Penitenciária Masculina Baldomero Cavalcanti de Oliveira uma cela denominada módulo de acolhimento.

No entanto, o isolamento dessas mulheres apresenta outro tipos de problemas,

Evidentemente, a criação da galeria é um fato que precisa ser comemorado e encarado, no contexto atual, como uma vitória da luta por direitos humanos. Mas não é obastante para que as travestis acessem um padrão melhor de cidadania, uma vez que o discurso da proteção e da segurança que a galeria traz não é de modo algum plenamente garantido pelo Estado, já que elas abrem mão de acessar outros direitos em detrimento de um reduto menos violento: passam a maior parte do dia enclausuradas [...] (AGUINSKY; FERREIRA; CIPRIANI, 2014, p. 301)

Observa-se assim, que as determinações da portaria foram cumpridas parcialmente. Inicialmente, observa-se pelos depoimentos dos agentes e reeducandos, que não há uma ala específica para o grupo LGBT, pois o chamado Módulo de Acolhimento, ou apenas acolhimento, conta com a ocupação pessoas LGBT, idosos e pessoas com adoecimento mental.
Desse modo, segundo o depoimento dos custodiados, Segundo relatos, o público que divide esse espaço com a população TRANS não seria fisicamente hostil, mas, também, não seria uma população com a qual haveria integração, além do importuno sexual e comportamento repressivo por parte dos idosos, bem como práticas precárias no tratamento dos doentes mentais.

Uma outra opção seria a transferência do público TRANS para outro módulo (denominado módulo 3), onde se encontram os custodiados que cometeram os crimes sexuais, pois são os únicos que aceitam convivência com o público LGBT. Assim sendo, a falta de espaço específico para LGBT produz a não aderência à política de criação de um módulo de acolhimento.

Salienta-se, neste contexto, eles ficam mais vulneráveis a sofrer violência interna, visto que quando há rebeliões internas, os primeiros alvos são os custodiados por crimes sexuais e o público LGBT.

Ainda convém lembrar, que embora estabelecido no $\S 2^{\circ}$ do artigo $8^{\circ}$ a faculdade de se usar o cabelos nos ombros e roupas de acordo com sua orientação sexual, depreende-se dos relatos dos próprios Agentes Penais, bem como dos custodiados TRANS, a obrigatoriedade de ser raspar a cabeça logo na triagem, inclusive com o uso 
de tratamento violento, além da imposição do uso de roupas masculinas.

$\mathrm{Na}$ verdade, apesar da existência da portaria como um meio de resguardar os direitos do público LGBT, não há qualquer garantia de que as práticas estipuladas estão sendo cumpridas.

\section{CONCLUSÃO}

Em virtude dos fatos mencionados, constatou-se que sistema penitenciário brasileiro se baseia no critério binário sexual para dividir os presos, ou seja, nossa população carcerária é dividida em homens e mulheres. Desse modo, existem inúmeras dificuldades, limites e críticas frente à realidade das mulheres transexuais encarceradas.

Dentro do sistema prisional, essas mulheres sofrem diversas violências não só pelos demais detentos com quem dividem o espaço prisional, mas também pelos agentes penais e diretores, que deveriam constitucionalmente garantir a proteção e a integridade física e psíquica de todos os custodiados.

Apesar de alguns avanços legislativos como julgados recentes do STJ E STF, não há um entendimento pacífico em relação ao cumprimento da pena nos
Neste Interim, faz-se necessário garantir a monitoração dos parâmetros estabelecidos na portaria, bem como a adequação das unidades aos parâmetros de acolhimento, para que possa haver o respeito aos direitos humanos de pessoas LGBT no sistema prisional alagoano.

presídios pelas mulheres Trans. Sendo assim, perene a teoria normativa do binarismo de gênero adotada pela sociedade, que continua restringindo o direito líquido e certo aos gêneros que contrariam o padrão, violando principalmente o princípio da dignidade da pessoa humana.

O Estado de Alagoas tem se destacado como um dos pioneiros no país, o qual possui uma política de atenção voltada para o segmento LGBT, estabelecendo parâmetros para o acolhimento desse público diante de sua orientação de gênero.

Há ainda uma longa caminhada a ser seguida em busca da preservação da dignidade da pessoa humana nos estabelecimentos prisionais. Não se objetiva, na verdade, um tratamento desigual, mas somente a possibilidade de se ter uma qualidade de vida e a garantia dos direitos básicos oferecidos a todos os outros alocados. 


\section{REFEFÊNCIAS}

ANDRADE, V.R. P. "Violência sexual e sistema penal. Proteção ou duplicação da vitimação feminina?", in: Feminino Masculino. Igualdade e Diferença na Justiça (Denise Dourado Dora, org.). Porto Alegre: Editora Sulina, 1997.

ARÁN, M.; MURTA, D.; LIONÇO, T. Transexualidade e Saúde Pública no Brasil. Ciênc. saúde coletiva, Rio de Janeiro, vol. 14, 2009. Disponível em:

htpps://www.scielo.br/scielo.php?scrip=art tex\&pid=S1413-81232009000400020.

Acesso em 21 set. 2020.

BENTO, B. O que é transexualidade. São Paulo: Brasiliense, 2008.

BENTO, B. Transviad@s: gênero, sexualidade e direitos humanos. Salvador: EDUFBA, 2017.

\section{BRASIL. Constituição da República} Federativa do Brasil De 1988. Disponível em:

http://www.planalto.gov.br/ccivil_03/Cons tituicao/Constituicao.htm. Acesso em: 22 julho 2020.

BRASIL. Pacto Internacional sobre Direitos Civis e Políticos. Disponível em: http://www.planalto.gov.br/ccivil_03/decre to/1990-1994/d0592.htm. Acesso em: 25 agosto 2020 .

BRASIL. Presidência da República; Conselho Nacional De Combate À Discriminação (CNCD). Resolução Conjunta no 1, de 15 de abril de 2014. Estabelece parâmetros de acolhimento de LGBT em privação de liberdade no Brasil. 2014.. Disponível em: http://www.lex.com.br/legis_25437433_R ESOLUCAO_CONJUNTA_N_1_DE_15 DE ABRIL_DE_2014.aspx . Acesso em: 30 agosto 2020 .

CONSELHO NACIONAL DE JUSTIÇA.
Regras de Bangkok Regras das Nações Unidas para o tratamento de mulheres presas e medidas não privativas de liberdade para mulheres infratoras. Série Tratados Internacionais de direitos humanos. Brasília, 2016. Disponível em: http://www.cnj.jus.br/

DIAS, M. B. Liberdade sexual e direitos humanos. In: Anais do III Congresso Brasileiro de Direito de Família: Família e cidadania. IBDFAM/OAB-MG, Belo Horizonte, 2002

FERREIRA, G. G. Políticas de tratamento penal para LGBTI+ no mundo. In: FERREIRA, G. G.; KLEIN, C. C.(Orgs.). Sexualidade e gênero na prisão: LGBTI+e suas passagens pela justiça criminal. Salvador: Devires, 2019.

GUIMARÃES, G. F. O transgênero e o gênero não-binário no sistema penal: suas convergências, influências e problematizações. 2014

LEVY, T. Crueldade e Crueza do Binarismo. In: CASCAIS, António Fernando (Org.).

Estudos Gays, Lésbicos e Queer. Lisboa: Fenda, 2004

MEDEIROS, P. A. A Realidade Do Sistema Prisional Brasileiro E A Ine Ficácia Da Pena Privativa De Liberdade: Uma Análise Humanitária. Monografia, [S.L], jun. 2016. Disponível em: https://monografias.ufma.br/jspui/bitstream /123456789/1642/1/PalomaMedeiros.pdf $>$. acesso em: 10 out. 2019

MORICI, S. Homossexualidade: um Lugar na História da Intolerância Social, um Lugar na Clínica. in Homossexualidade. Formulações Psicanalíticas Atuais. Porto Alegre: Artmed. 2020

PINTO, M. J.C.; BRUNS, M.A.T. Vivência transexual: o corpo desvela seu 
drama. Rio de Janeiro: Átomo, 2003

PRINCÍPIOS DE YOGYAKARTA.

Princípios sobre a aplicação da legislação internacional de direitos humanos em relação à orientação sexual e identidade de gênero. Disponível em: http://www.clam.org.br/uploads/conteudo/ principios_de_yogyakarta.pdf

RODRIGUES. F. "Sistema Penitenciário E Exclusão Social: Um Olhar Sobre A Realidade Das Prisões Brasileiras". Jacarezinho. 2012

SANTOS, I. P. R.; GOMES, C. M.

Travestis no sistema carcerário do Distrito Federal: gênero e cárcere entre narrativas e normas. Revista Brasileira de Ciências Criminais, São Paulo, v. 146, 2018.
Disponível em:

https://bdjur.tjdft.jus.br/xmlui/handle/tjdft/ 41236. Acesso em: 09 jul. 2020

SANTOS, T. Levantamento Nacional de Informações Penitenciárias (INFOPEN). Brasília, DF: Ministério da Justiça, 2017.Disponível em: http://depen.gov.br/DEPEN/noticias$\underline{1 / \text { noticias/infopen-levantamento-nacional- }}$ informacoes-penitenciarias6/relatorio_2016_22111.pdf Acesso em: 07 maio 2020

STF. ADI 4275-1/600. Disponível em http://www.stf.jus.br/portal/geral/verPdfPa ginado.asp?id=400211\& tipo=TP\&descrica $\mathrm{o}=\mathrm{ADI} \% 2 \mathrm{~F} 4275>$. Acesso em 18 Set. 2019 vão, 2009. Anais...São Cristóvão: [s.n.], 2009. 